\title{
Novel Genes for Airway Wall Thickness Identified with Combined Genome-Wide Association and Expression Analyses
}

\author{
Akkelies E. Dijkstra ${ }^{1,2}$, Dirkje S. Postma ${ }^{1,2}$, Bram van Ginneken ${ }^{3,4}$, Mark O. Wielpütz ${ }^{5,6,7}$, Michael Schmidt ${ }^{4}$, \\ Nikolaus Becker ${ }^{8}$, Michael Owsijewitsch ${ }^{5,6,7}$, Hans-Ulrich Kauczor ${ }^{5,6}$, Harry J. de Koning ${ }^{9}$, Jan W. Lammers ${ }^{10}$, \\ Matthijs Oudkerk ${ }^{11}$, Corry-Anke Brandsma ${ }^{2,12}$, Yohan Bossé ${ }^{13}$, David C. Nickle ${ }^{14}$, Don D. Sin ${ }^{15}$, Pieter S. Hiemstra ${ }^{16}$, \\ Ciska Wijmenga ${ }^{17}$, Joanna Smolonska ${ }^{2,17}$, Pieter Zanen ${ }^{10}$, Judith M. Vonk ${ }^{2,18}$, Maarten van den Berge ${ }^{1,2}$, \\ H. Marike Boezen ${ }^{2,18}$, and Harry J. M. Groen ${ }^{1}$
}

${ }^{1}$ Department of Pulmonary Diseases, ${ }^{2}$ Groningen Research Institute for Asthma and Chronic Obstructive Pulmonary Disease, ${ }^{11}$ Department of Radiology, ${ }^{12}$ Department of Pathology, ${ }^{17}$ Department of Genetics, and ${ }^{18}$ Department of Epidemiology, University Medical Center Groningen, University of Groningen, Groningen, The Netherlands; ${ }^{3}$ Department of Radiology, Radboud University Medical Center, Nijmegen, The Netherlands; ${ }^{5}$ Department of Diagnostic and Interventional Radiology, University of Heidelberg, Heidelberg, Germany; ${ }^{6}$ Translational Lung Research Center Heidelberg, Member of the German Center for Lung Research, Heidelberg, Germany; ${ }^{4}$ Fraunhofer MEVIS, Institute for Medical Image Computing, Bremen, Germany; ${ }^{7}$ Department of Radiology and ${ }^{8}$ Division of Cancer Epidemiology, German Cancer Research Center, Heidelberg, Germany; ${ }^{9}$ Department of Public Health, Erasmus Medical Center Rotterdam, Rotterdam, The Netherlands; ${ }^{10}$ Department of Pulmonology, University Medical Center Utrecht, University of Utrecht, Utrecht, The Netherlands; ${ }^{13}$ Department of Molecular Medicine, Institut Universitaire de Cardiologie et de Pneumologie de Québec, Laval University, Québec City, Québec, Canada; ${ }^{14}$ Merck Research Laboratories, Boston, Massachusetts; ${ }^{15}$ Division of

Respirology, Department of Medicine, James Hogg Research Centre, St. Paul's Hospital, University of British Columbia, Vancouver, British Columbia, Canada; and ${ }^{16}$ Department of Pulmonology, Leiden University Medical Center, Leiden, The Netherlands

\begin{abstract}
Rationale: Airway wall thickness (AWT) is affected by both environmental and genetic factors and is strongly associated with airflow limitation in smaller airways.
\end{abstract}

Objectives: To investigate the genetic component of AWT.

Methods: AWT was measured on low-dose computed tomography scans in male heavy smokers participating in a lung cancer screening study $(\mathrm{n}=2,640)$. Genome-wide association studies on AWT were performed under an additive model using linear regression (adjusted for pack-years, lung volume), followed by metaanalysis. An independent cohort was used for validation of the most strongly associated single-nucleotide polymorphisms (SNPs). The functional relevance of significant SNPs was evaluated.

Measurements and Main Results: Three significant loci on chromosomes $2 \mathrm{q}\left(\mathrm{rs} 734556 ; P=6.2 \times 10^{-7}\right)$ and $10 \mathrm{q}(\mathrm{rs} 10794108$,
$P=8.6 \times 10^{-8} ;$ rs7078439, $P=2.3 \times 10^{-7}$ ) were associated with AWT and confirmed in the metaanalysis in cohorts with comparable lung function: $P$ values $=4.6 \times 10^{-8}, 7.4 \times 10^{-8}$, and $7.5 \times 10^{-8}$, respectively. SNP rs734556 was associated with decreased lung tissue expression of SERPINE2, a susceptibility gene for emphysema. Two nominally significant SNPs showed effects with similar direction: rs10251504 in MAGI2 $\left(P=5.8 \times 10^{-7}\right)$ and rs4796712 in NT5C3B $\left(P=3.1 \times 10^{-6}\right)$. Higher MAGI2 expression in bronchial biopsies of patients with chronic obstructive pulmonary disease was significantly associated with fewer inflammatory cells. The presence of the $N T 5 C 3 B$ risk allele was associated with higher lung tissue expression $\left(P=1.09 \times 10^{-41}\right)$.

Conclusions: Genetic variants contribute to AWT. Among others, the identified genes are also involved in emphysema, airway obstruction, and bronchial inflammation.

Keywords: airway wall thickening; CT scan; genetics; COPD; smoking

(Received in original form May 10, 2014; accepted in final form December 12, 2014)

Author Contributions: Study design, A.E.D., D.S.P., H.M.B., and H.J.M.G. Phenotype data acquisition and quality control, A.E.D., M.O.W.,

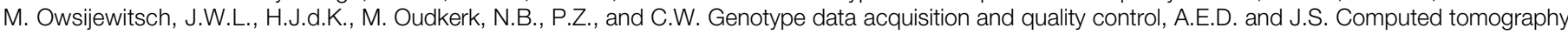

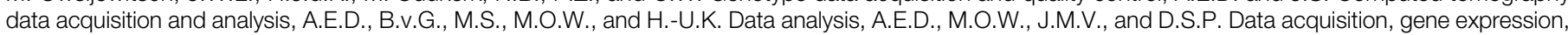
and expression quantitative trait loci analysis, M.v.d.B., D.S.P., P.S.H., Y.B., C.-A.B., D.D.S., and D.C.N.

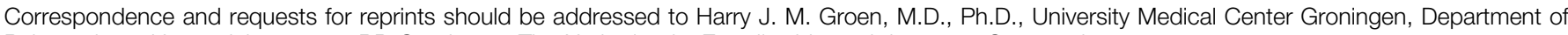
Pulmonology, Hanzeplein 1, 9700 RB Groningen, The Netherlands. E-mail address: h.j.m.groen@umcg.nl

This article has an online supplement, which is accessible from this issue's table of contents at www.atsjournals.org

Am J Respir Crit Care Med Vol 191, Iss 5, pp 547-556, Mar 1, 2015

Copyright @ 2015 by the American Thoracic Society

Originally Published in Press as DOI: 10.1164/rccm.201405-08400C on December 17, 2014

Internet address: www.atsjournals.org 


\section{At a Glance Commentary}

\section{Scientific Knowledge on the \\ Subject: The genetic and}

environmental influences that induce cellular and molecular changes leading to airway wall thickening and remodeling are poorly understood.

\section{What This Study Adds to the}

Field: Our study provides evidence that airway wall thickness quantified on low-dose computed tomography is associated with a genetic predisposition. MAGI2, SERPINE2, and $N T 5 C 3 B$ expression levels are associated with airway wall thickening and additionally with bronchial inflammation, emphysema, and lung function, respectively, all features of chronic obstructive pulmonary disease.

Airway wall thickening can occur over the total length of the respiratory tract and is associated with chronic mucus hypersecretion in larger airways and with airway obstruction in smaller airways (1). The pathologic process underlying airway wall thickening is chronic inflammation and remodeling of the airway wall caused by external factors, such as cigarette smoke and occupational exposures.

Not every heavy smoker develops airway wall thickening and subsequent airway obstruction. Therefore, a genetic predisposition may play a role in the origin of this phenomenon. This is supported by a familial aggregation study (2) and by the association of several chronic obstructive pulmonary disease (COPD) candidate genes with airway wall thickening in another study (3).

In the past, knowledge on the process of airway wall thickening was mainly obtained through autopsy and bronchoscopic biopsy studies. Nowadays, computed tomography (CT) can be used to more accurately measure the dimensions of the airway wall. Previous studies using low-dose CT have assessed airway dimensions, such as lumen area or diameter, or Pi10 with different airway sampling methods, particularly in relation to airflow limitation, respiratory symptoms, emphysema, and smoking habits (4). Research by Nakano and colleagues (1) revealed that CT measurements of larger airways could be used to estimate the dimensions of the small conducting airways. Therefore, airway wall thickness (AWT) measurements may reflect the dimensions of smaller airways, the main source of airway obstruction in COPD (1). AWT in COPD depends on the patient population and methods used to measure AWT (5-7). We used the actually measured AWT at a fixed lumen diameter in all lobes (4).

The aim of the present study was to identify which genetic variants are associated with increased AWT measured with low-dose CT in a cohort of male heavy current and ex-smokers participating in the Dutch-Belgian lung cancer screening trial (NELSON). We subsequently validated our findings in the German Lung Cancer Screening Intervention Trial (LUSI), thereby obtaining better insights in the origins of airway wall thickening that contributes to the development of $\operatorname{COPD}(8,9)$.

\section{Methods}

\section{Ethics Statement}

The Dutch Ministry of Health and the Medical Ethics Committee of the hospital approved the study protocol for all Dutch centers. Ethics approval and written informed consent was obtained from all participants in the studies. Details are provided in the online supplement.

\section{Population}

Male participants from Groningen and Utrecht were recruited from the Dutch NELSON study, a heavy smoking population-based lung cancer screening trial. Detailed inclusion criteria and characteristics have been described elsewhere (8). In short, individuals with a smoking history of greater than or equal to 20 pack-years obtained by a standardized questionnaire were included. To confirm the results of the analyses performed in participants of the NELSON study, additional analyses were performed in subjects participating in the LUSI, an epidemiologic study among men and women with a history of heavy smoking $(\geqslant 20$ pack-years) (9).

\section{CT Scanning and Defining Four Study Groups}

Low-dose CTs of the chest were acquired in full inspiration after appropriate instruction without using contrast medium. CT images were attained with 16-row detector scanners (Sensation 16; Siemens Medical Solutions, Forchheim, Germany)

(Groningen NELSON population, group I) or Brilliance 16P (Philips Medical Systems, Cleveland, $\mathrm{OH}$ ) (Utrecht NELSON

population, group II). CT acquisition for the LUSI trial was performed from 2007 to 2010 with a 16-row scanner (Aquilion 16; Toshiba Corp., Tokyo, Japan) (LUSI, group III), and from 2010 to 2012 with a 128-row detector scanner (Somatom Definition Flash; Siemens Medical Solutions) (LUSI, group IV). All CT systems were calibrated routinely. CT scanning settings in NELSON and LUSI were previously described $(8,9)$.

\section{Lung Function}

Spirometry according to the European Respiratory Society guidelines (10), including $\mathrm{FEV}_{1}$ and $\mathrm{FVC}$, was performed at the start of the study.

\section{Quantification of Airway Dimensions and Lung Volume}

AWT was measured in cross-sectionally reformatted images with an automated research software prototype MEVIS Airway Examiner v1.0 (release 2009; Fraunhofer MEVIS, Bremen, Germany) at locations

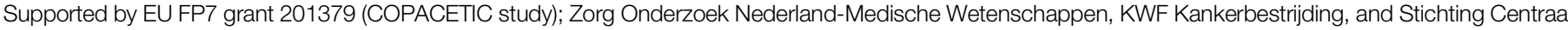

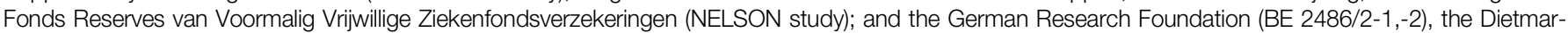

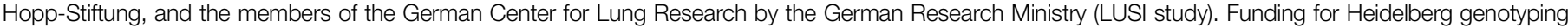
was provided by Stichting Astma Bestrijding. The GLUCOLD study was supported by the Netherlands Organization for Scientific Research, Netherlands

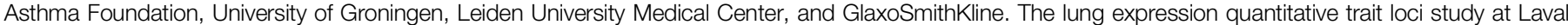

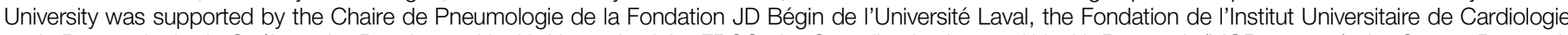

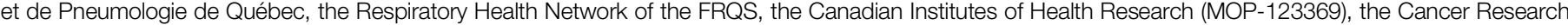
Society, and Read for the Cure. Y. Bossé is the recipient of a Junior 2 Research Scholar award from the Fonds de Recherche Québec-Santé. 
with an internal diameter of $3.5 \mathrm{~mm}$ in each lung lobe as described previously (4). More detailed information is provided in the online supplement.

Quantification of lung volume was based on automatic lung segmentation provided by a software tool called ImageXplorer (Image Sciences Institute, Utrecht, The Netherlands) (11). CTs were evaluated for appropriate segmentation. The mean AWT at $3.5-\mathrm{mm}$ internal lumen size $\left(\mathrm{AWT}_{3.5}\right)$ of all five lobes per case was calculated taking into account the fraction of perimeter where the outer wall border was identified (assessed perimeter fraction [APF]) per lobe by the following formulae: (AWT left upper lobe $\times$ APF left upper lobe $)+($ AWT left lower lobe $\times$ APF left lower lobe $)+($ AWT right upper lobe $X$ APF right upper lobe) + (AWT right middle lobe $\times$ APF right middle lobe $)+$ (AWT right lower lobe $\times$ APF right lower lobe)/sum of APF of all lung lobes, as published previously (4). $\mathrm{AWT}_{3.5}$ for the whole population is not normally distributed, therefore we report median AWT and range, and log-transformed AWT was used in the analyses.

\section{Genome-Wide Association Study in the Identification Cohort}

Group I and II individuals were genotyped using the Illumina Quad 610 array (Illumina Inc., San Diego, CA) containing more than 620,000 single-nucleotide polymorphisms
(SNPs). A genome-wide association (GWA) study of AWT was performed separately in groups I and II to correct for differences in CT scanners. Subsequently, results of these analyses were metaanalyzed.

\section{Replication of Top SNPs in an Independent Cohort}

Forty-eight SNPs $\left(P<10^{-4}\right)$ not in strong linkage disequilibrium $\left(r^{2} \geqslant 0.80\right)$ with other top SNPs were genotyped in groups III and IV using a custom made VeraCode assay (Illumina). As two different scanners were used in groups III and IV, two separate replication analyses were performed using a similar model with additional adjustment for sex (because females were also included in this cohort). Finally, a metaanalysis was performed on top SNPs across groups I, II, III, and IV.

To replicate the findings in homogeneous populations, the analysis was repeated by excluding group III and IV women, and by selecting individuals of groups III and IV with lung function values of $\mathrm{FEV}_{1} /$ FVC less than $80 \%$, comparable with the lung function values in groups I and II.

\section{Functional Relevance of the Identified Top SNPs}

We assessed whether the identified top SNPs were expression quantitative trait loci (eQTL) by analyzing the association of gene expression levels with SNP genotypes in lung tissue from three independent cohorts recruited from Laval University, University of British Columbia, and University of Groningen as described previously (12).

Additionally, we assessed whether messenger RNA (mRNA) expression of the top genes in bronchial biopsies from 79 participants with COPD in the GLUCOLD study were associated with lung function $\left(\mathrm{FEV}_{1} \%\right.$ predicted) and bronchial biopsy inflammatory cells $(13,14)$. Details on the methods of the functional studies are given in the online supplement.

\section{Statistical Analysis}

General characteristics of the participants and differences between the cohorts were calculated with SPSS 20.0 (SPSS Inc., New York, NY).

Quality control (QC), regression analyses, and metaanalyses were performed with PLINK 1.07 (http://pngu.mgh.harvard. edu/purcell/plink/) (15). SNPs with call rate less than $95 \%$, minor allele frequency less than 0.05 , proportion of individuals for which no genotype was called (mind) less than 0.95, and Hardy Weinberg equilibrium less than 0.0001 were excluded. Ethnic outliers, duplicates, and relatives were removed. In LUSI, QC was similar except for mind, which was set to less than 0.9 (exclusion of individuals with $<90 \%$ of genotypes)

Linear regression analysis under an additive genetic model, with adjustment for pack-years and lung volume, was used to

Table 1. Demographic and Clinical Characteristics of the Groups I and II NELSON Identification and Groups III and IV LUSI Replication Populations

\begin{tabular}{|c|c|c|c|c|}
\hline & \multicolumn{2}{|c|}{ NELSON } & \multicolumn{2}{|c|}{ LUSI } \\
\hline & Group I & Group II & Group III & Group IV \\
\hline $\mathrm{N}$ & 1,513 & 1,127 & 488 & 226 \\
\hline \multicolumn{5}{|l|}{ Characteristics } \\
\hline Age, yr & $59.9(5.4)$ & $60.8(5.5)$ & $57.1(5.2)$ & $53.1(4.4)$ \\
\hline Height, cm & $178.9(6.1)$ & $178.2(6.6)$ & $173.3(8.6)$ & $173.2(8.6)$ \\
\hline Male sex, \% & 100 & 100 & 66.0 & 59.9 \\
\hline \multicolumn{5}{|l|}{ Smoking } \\
\hline Pack-years smoking & $38(21-140)$ & $40(22-140)$ & 37 (19-146) & 33 (19-104) \\
\hline Current smoking, \% & 57.2 & 55.0 & 60.2 & 67.6 \\
\hline \multicolumn{5}{|l|}{ Lung function } \\
\hline $\mathrm{FEV}_{1}, \mathrm{~L}$ & $3.46(0.74)$ & $3.28(0.71)$ & $2.88(0.78)$ & $2.93(0.78)$ \\
\hline FEV $_{1} / F V C, \%$ & $71.9(9.8)$ & $71.4(9.4)$ & $78.6(9.5)$ & $79.3(11.7)$ \\
\hline $\mathrm{FEV}_{1}, \%$ predicted & $99.2(18.7)$ & $95.8(17.7)$ & $91.6(19.6)$ & $91.2(17.0)$ \\
\hline \multicolumn{5}{|l|}{ CT measurements } \\
\hline Median AWT, mm & $0.57(0.28-1.72)$ & $0.60(0.28-1.76)$ & $0.57(0.31-1.36)$ & $0.60(0.34-1.20)$ \\
\hline Lung volume, L & $6.71(1.2)$ & $6.83(1.4)$ & $5.52(1.8)$ & $5.80(1.3)$ \\
\hline
\end{tabular}

Definition of abbreviations: AWT = airway wall thickness at 3.5-mm internal lumen size; CT = computed tomography; LUSI = German Lung Cancer Screening Intervention Trial; NELSON = Dutch-Belgian lung cancer screening trial.

Mean ( $\pm \mathrm{SD}$ ) shown for continuous data and median (range) for nonparametric distribution. 
Table 2. Association between AWT in the Different Lobes within Individuals across NELSON (Groups I and II)

\begin{tabular}{|c|c|c|c|c|c|}
\hline & $\begin{array}{l}\text { AWT Right } \\
\text { Upper Lobe }\end{array}$ & $\begin{array}{l}\text { AWT Right } \\
\text { Middle Lobe }\end{array}$ & $\begin{array}{l}\text { AWT Right } \\
\text { Lower Lobe }\end{array}$ & $\begin{array}{l}\text { AWT Left } \\
\text { Upper Lobe }\end{array}$ & $\begin{array}{l}\text { AWT Left } \\
\text { Lower Lobe }\end{array}$ \\
\hline \multicolumn{6}{|l|}{ AWT right upper lobe } \\
\hline $\begin{array}{l}\text { Correlation coefficient } \\
P \text { value }\end{array}$ & & $\begin{aligned} & 0.81 \\
< & 0.001\end{aligned}$ & $\begin{aligned} & 0.87 \\
< & 0.001\end{aligned}$ & $\begin{array}{c}0.91 \\
<0.001\end{array}$ & $\begin{array}{r}0.835 \\
<0.001\end{array}$ \\
\hline \multicolumn{6}{|l|}{ AWT right middle lobe } \\
\hline $\begin{array}{l}\text { Correlation coefficient } \\
P \text { value }\end{array}$ & $\begin{array}{c}0.81 \\
<0.001\end{array}$ & 1.00 & $\begin{aligned} & 0.81 \\
< & 0.001\end{aligned}$ & $\begin{aligned} & 0.80 \\
< & 0.001\end{aligned}$ & $\begin{aligned} & 0.4 \\
< & 0.001\end{aligned}$ \\
\hline \multicolumn{6}{|l|}{ AWT right lower lobe } \\
\hline $\begin{array}{l}\text { Correlation coefficient } \\
P \text { value }\end{array}$ & $\begin{aligned} & 0.87 \\
< & 0.001\end{aligned}$ & $\begin{aligned} & 0.81 \\
< & 0.001\end{aligned}$ & 1.00 & $\begin{aligned} & 0.86 \\
< & 0.001\end{aligned}$ & $\begin{aligned} & 0.90 \\
< & 0.001\end{aligned}$ \\
\hline \multicolumn{6}{|l|}{ AWT left upper lobe } \\
\hline $\begin{array}{l}\text { Correlation coefficient } \\
P \text { value }\end{array}$ & $\begin{array}{c}0.91 \\
<0.001\end{array}$ & $\begin{array}{l}0.80 \\
<0.001\end{array}$ & $\begin{array}{l}0.86 \\
<0.001\end{array}$ & 1.00 & $\begin{array}{c}0.87 \\
<0.001\end{array}$ \\
\hline \multicolumn{6}{|l|}{ AWT left lower lobe } \\
\hline $\begin{array}{l}\text { Correlation coefficient } \\
P \text { value }\end{array}$ & $\begin{aligned} & 0.84 \\
< & 0.001\end{aligned}$ & $\begin{aligned} & 0.78 \\
< & 0.001\end{aligned}$ & $\begin{aligned} & 0.90 \\
< & 0.001\end{aligned}$ & $\begin{aligned} & 0.87 \\
< & 0.001\end{aligned}$ & 1.00 \\
\hline
\end{tabular}

Definition of abbreviations: AWT = airway wall thickness; NELSON = Dutch-Belgian lung cancer screening trial.

identify SNPs associated with AWT. SNPs were included for replication if there was a strong association with AWT (top SNP; $\left.P<10^{-4}\right)$. When two top SNPs were in strong linkage disequilibrium $\left(r^{2} \geqslant 0.8\right)$, the SNP with the lowest $P$ value was followed up. Metaanalysis was performed using a fixed-effect model.

\section{Results}

\section{Study Populations}

Characteristics of the identification and replication populations are presented in Table 1. After QC, 1,513 individuals in group I and 1,127 individuals in group II, and 522,636 SNPs were included in the analyses. In the replication analyses 714 individuals, 488 in group III and 226 in group IV, were included after QC. Median AWT on CTs was comparable in all cohorts studied. There was a strong association between AWT in the different lobes within individuals across NELSON (groups I and II) (Table 2). In groups I and II $82 \%$ of cases had an $\mathrm{FEV}_{1} / \mathrm{FVC}$ less than $80 \%$ and $52 \%$ of cases in groups III and IV.

For comparison with groups I and II we provide the characteristics of subgroups of III and IV with males only, or including individuals with an $\mathrm{FEV}_{1} / \mathrm{FVC}$ less than $80 \%$ (see Table E1 in the online supplement).

\section{Identification and Replication Analysis}

Genome-wide analysis in groups I and II and the subsequent metaanalysis showed 69 SNPs to be associated with AWT $(P \leqslant$ $\left.10^{-4}\right)$. The QQ-plot provided no evidence of population stratification $(\lambda=1.012)$ (Figure 1). GWA for AWT ordered by chromosome is shown in the Manhattan plot (Figure 1). Identification analysis of AWT per lobe did not show any regional heterogeneity (see Figures E1-E5).

The lowest $P$ value was found for rs10794108 on chromosome 10q $\left(P=8.60 \times 10^{-8}\right.$ located between the Chromosome 10 open reading frame 90 (C10orf90, distance $200 \mathrm{~kb}$ ) and the
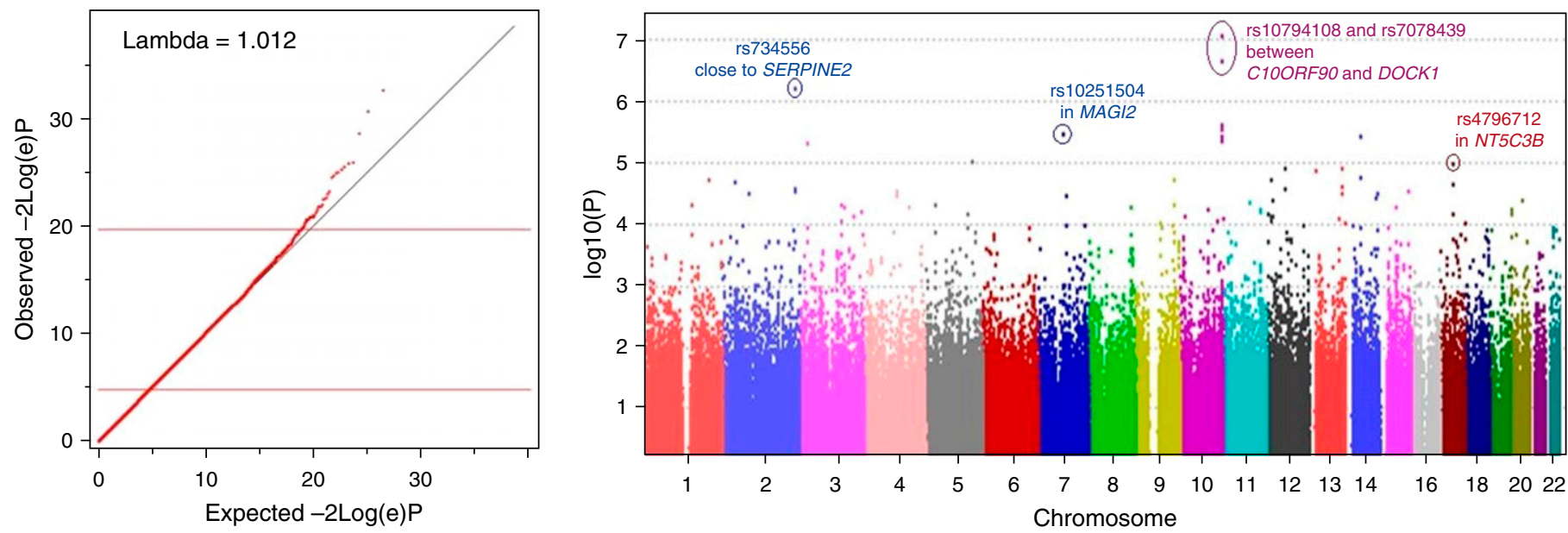

Figure 1. Quantile-quantile plot (left) and Manhattan plot (right) of genome-wide association results for association of single-nucleotide polymorphisms with airway wall thickness in the metaanalysis in the Dutch-Belgian lung cancer screening trial (NELSON). 


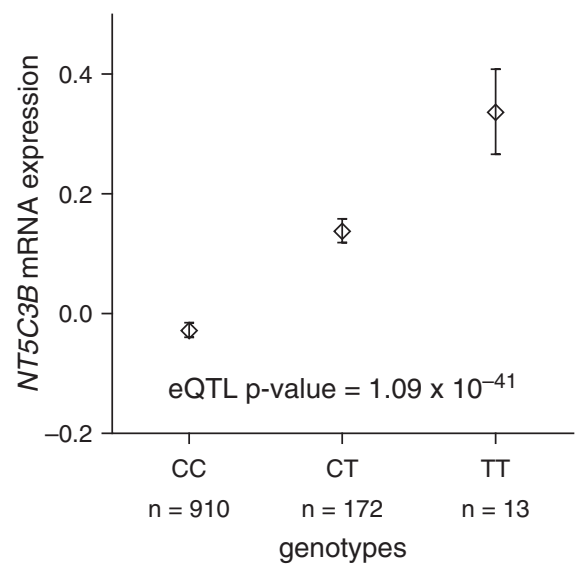

Figure 2. Boxplots of lung gene expression levels for NT5C3B according to genotype groups for single-nucleotide polymorphism rs4796712 in 1,095 individuals. eQTL $=$ expression quantitative trait loci; $\mathrm{mRNA}=$ messenger RNA.

Dedicated of Cytokinesis gene (DOCK1, distance $355 \mathrm{~kb}$ ). Table E2 displays SNPs in association with AWT with a $P$ value less than $10^{-4}$

Based on the statistical significance of the association with AWT and presence of linkage disequilibrium between SNPs, 48 SNPs were selected for replication in groups III and IV. Out of these SNPs, one SNP (rs507098) did not pass QC. The other 47 SNPs were associated with AWT as measured in groups I and II and followed by metaanalysis. The 14 top SNPs from this analysis are shown in Table 3 (see Table E3 for all $47 \mathrm{SNPs}$ ).

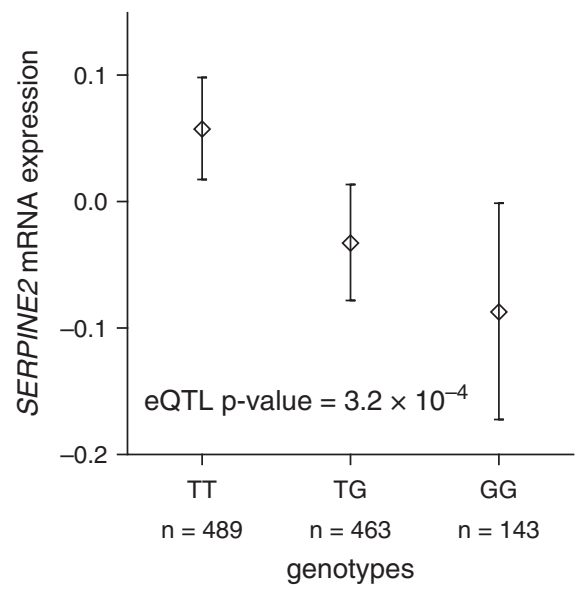

Figure 3. Boxplots of lung gene expression levels for SERPINE2 according to genotype groups for single-nucleotide polymorphism rs734556 in 1,095 individuals. eQTL = expression quantitative trait loci; $\mathrm{mRNA}=$ messenger RNA.
The metaanalysis in groups I, II, III, and IV provided six SNPs with a $P$ value less than $10^{-5}$ including two SNPs with effects in the same direction in all four cohorts analyzed:

1. rs10251504 on chromosome 7q21, an intronic SNP in the membrane associated guanylate kinase $W W$ and $P D Z$ domain containing 2 gene $\left(\right.$ MAGI2); $P$ value $=5.79 \times 10^{-7}$, $\beta=0.035$.

2. rs4796712 on chromosome $17 \mathrm{q} 21.2$, an intronic SNP located in an intron in the 5 '-nucleotidase, cytosolic IIIB (NT5C3B) gene; $P$ value $=3.11 \times 10^{-6}, \beta=0.052$.

Replication analyses including males

from groups III and IV only $(\mathrm{n}=457)$ and subsequent metaanalysis in groups I, II, III, and IV showed comparable results (see Table E4).

Replication analyses in individuals from groups III and IV with an $\mathrm{FEV}_{1} / \mathrm{FVC}$ less than $80 \%(\mathrm{n}=374)$ and subsequent metaanalysis in groups I, II, III, and IV showed stronger associations between several SNPs and AWT compared with the initial analysis, counting three SNPs with genome-wide significant associations, despite the smaller sample size (reducing from $\mathrm{n}=3,354$ to $\mathrm{n}=3,014$ ):

1. rs734556, an SNP located between the secretogranin II gene (SCG2) and the adaptor-related protein complex 1 ( $\sigma$ 3 subunit) gene (AP1S3) and close to the WD repeat and FYVE domain containing 1 (WDFY1) gene, the mitochondrial ribosomal protein L44 (MRPL44) gene, and the serpin peptidase inhibitor, clade E member 2 (SERPINE2) gene on chromosome $2 \mathrm{q}$ (see Figure $6 \mathrm{E}$ ); $P$ value $=4.60 \times 10^{-8}, \beta=0.043$.

2. rs7078439 and rs10794108, located between C10orf 90 and DOCK1 (distance $3,889 \mathrm{~kb}$; moderate linkage disequilibrium; $r^{2}=0.82$ ) on chromosome $10 \mathrm{q} ; P$ values $=7.44 \times$ $10^{-8}, \beta=0.047$ and $7.53 \times 10^{-8}$, $\beta=0.044$, respectively.

The top 12 SNPs from this analysis are shown in Table 4, and all 47 replicated SNPs in Table E5.

\section{Functional Analyses on SNPs and Corresponding Genes Identified in the Initial Analysis}

We found a strong significant association between rs4796712 and the lung mRNA expression levels of NT5C3B (Affymetrix
ID: 100128528-TGI-at; Ensemble ID: NM_052935). The presence of the (susceptibility) $\mathrm{T}$ allele was significantly associated with a higher NT5C $3 B$ mRNA expression (genotypes, $\mathrm{CC}=910, \mathrm{TC}=172$, TT $\left.=13 ; P=1.09 \times 10^{-41} ; \beta=0.910\right)$ (Figure 2). There was no significant association between rs10251504 and MAGI2 expression.

Subsequently, NT5C3B and MAGI2 expression were assessed in airway wall biopsies of patients with COPD who did not use inhaled corticosteroids in GLUCOLD. Both mRNA expression levels were correlated with lung function and bronchial biopsy inflammatory markers. Higher MAGI2 mRNA expression was significantly associated with lower numbers of inflammatory cells: macrophages $\left(P=1.08 \times 10^{-2}\right)$, CD3 lymphocytes $\left(P=1.57 \times 10^{-2}\right), \mathrm{CD} 4$ lymphocytes $\left(P=4.08 \times 10^{-4}\right)$, CD8 lymphocytes $(P=$ $\left.4.22 \times 10^{-3}\right)$, and $\%$ intact epithelial cells $\left(P=1.24 \times 10^{-3}\right)$ but not with eosinophils $(P=0.72)$ or mast cells $\left(P=9.7 \times 10^{-2}\right)$.

MAGI2 mRNA expression was not associated with airway obstruction (postbronchodilator $\mathrm{FEV}_{1} \%$ predicted, $P=0.42$ ). Less NT5C3B mRNA expression was significantly associated with airway obstruction (post-bronchodilator $\mathrm{FEV}_{1} \%$ predicted, $P=3.17 \times 10^{-2}$ ) but not with any of the inflammatory cells (macrophages, mast cells, CD3-, CD4-, CD8-lymphocytes or percent intact epithelial cells; $P=0.14,0.33,0.66,0.66$, $0.83,0.76$ respectively).

\section{Functional Analyses on SNPs and Corresponding Genes Identified in Individuals with Comparable Lung Function}

In individuals with comparable lung function rs734556 was significantly associated with SERPINE2 mRNA expression (Affymetrix ID: 100307061_TGI_at; Ensemble ID: BQ876560). The (susceptibility) T allele was significantly associated with lower SERPINE2 mRNA expression (genotypes, $\mathrm{TT}=489, \mathrm{TG}=463, \mathrm{GG}=143 ; P=3.21 \times$ $10^{-4} ; \beta=0.153$ ) (Figure 3). However, SERPINE2 mRNA expression in the bronchial wall biopsies of patients with COPD (GLUCOLD) was not related to airway obstruction $(P=0.43)$.

We did not find significant associations of rs10794108 and rs7078439 genotypes with C10orf90 and DOCK1 expression 


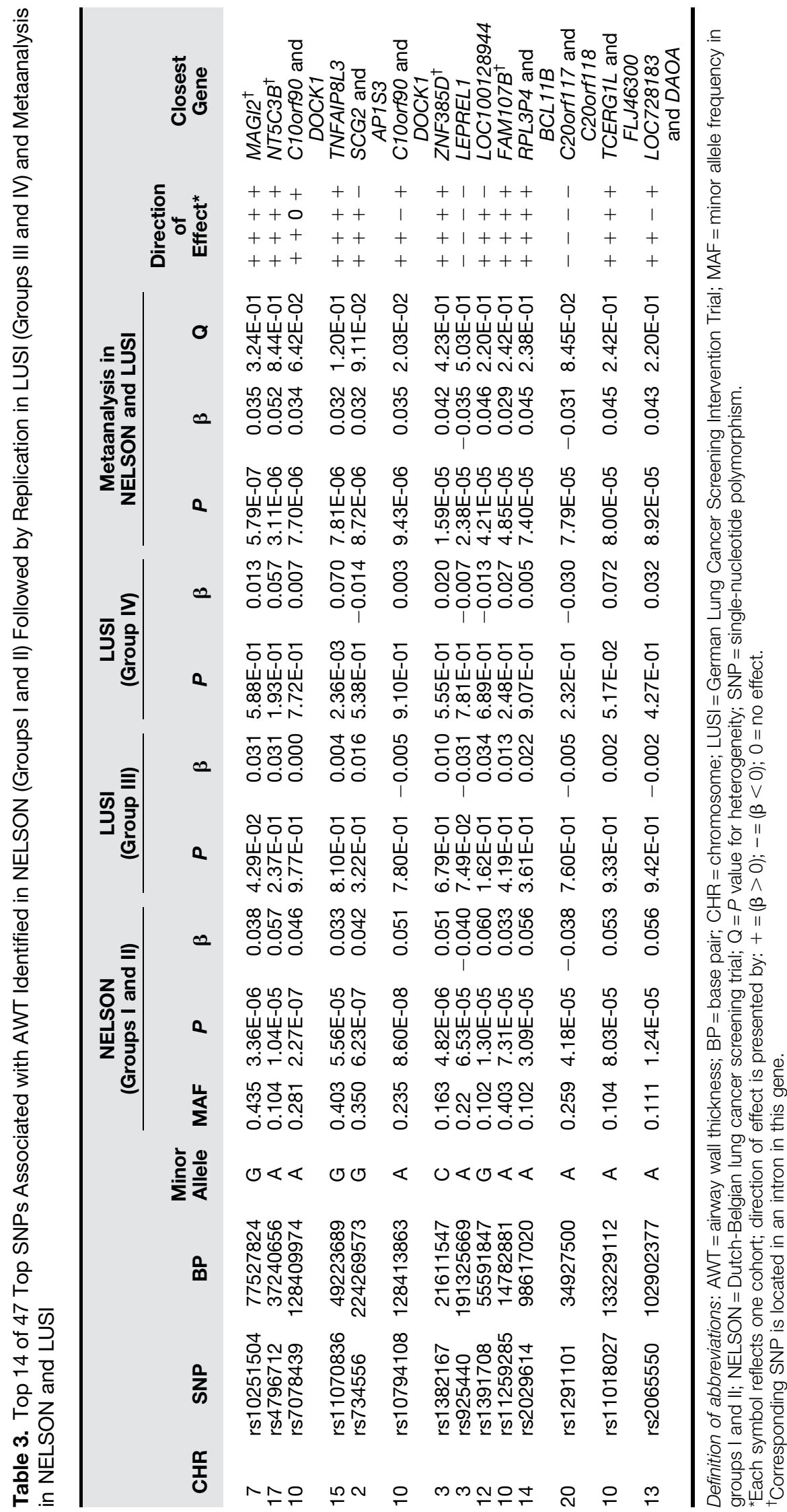




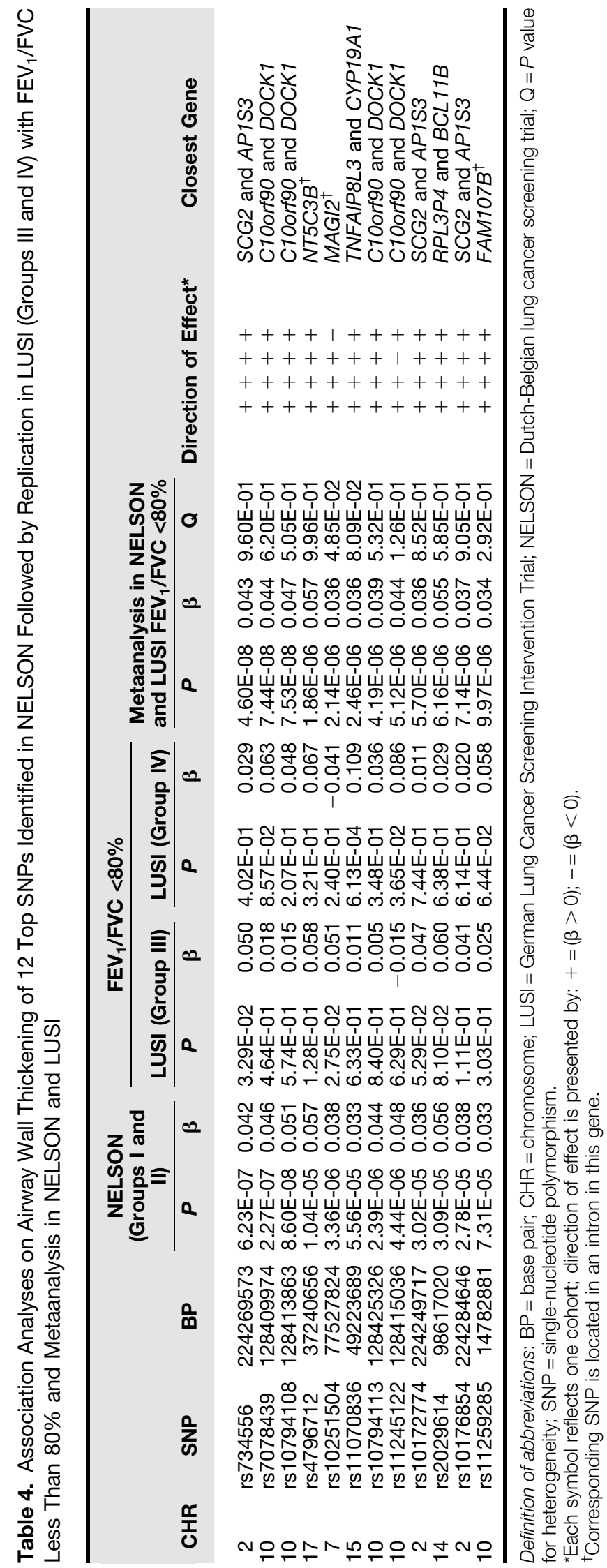


Table 5. Association of SNP Genotypes with Gene Expression Levels in Lung Tissue $(n=1,095)$

\begin{tabular}{lclrrrrr}
\hline SNP & Risk Allele & eQTL Gene & Position SNP & Start eQTL & Stop eQTL & \multicolumn{1}{c}{$\boldsymbol{\beta}$} & $\boldsymbol{P}$ Value \\
& & & & & & & \\
rs4796712 & T & NT5C3B & 37240656 & 37240656 & 37246017 & 0.910 & $1.09 \mathrm{E}-41$ \\
rs734556 & G & SERPINE2 & 224269573 & 224548538 & 224564865 & -0.153 & $3.21 \mathrm{E}-4$ \\
\hline
\end{tabular}

Definition of abbreviations: $\mathrm{eQTL}=$ expression quantitative trait loci; SNP = single-nucleotide polymorphism.

levels in lung tissue, or of rs734556 genotypes with SCG2, AP1S3 and WDFY1 expression levels. An overview of the results of the functional analyses is given in Tables 5 and 6.

\section{Discussion}

To our knowledge, this is the first study that provides evidence for genetic origins of CT-quantified AWT, an important contributing factor for airway obstruction and development of COPD. We identified two SNPs (rs10251504 and rs4796712) associated with AWT showing effects in the same direction in both the identification and replication cohort. Moreover, when selecting individuals in the replication cohort (LUSI) with a comparable lung function as those in the identification cohort (NELSON) (82\% of cases with $\mathrm{FEV}_{1}$ / FVC $<80 \%$ ), three SNPs (rs734556, rs7078439, and rs10794108) reached genome-wide significance in the metaanalysis in the cohorts studied. There was no significant heterogeneity in genomic associations for AWT per lobe indicating that the genetic signal is present in all lobes.

In our study we also discovered in the identification cohort two SNPs, rs10794108 and rs7078439, located near each other in a "desert" between two genes (C10orf90 and DOCK1) strongly associated with AWT. The SNP rs10794108 was found previously to be associated with severity of airway obstruction $\left(\mathrm{FEV}_{1} / \mathrm{FVC}<90 \%\right.$ predicted and $\mathrm{FEV}_{1}<80 \%$ predicted) in a GWA study performed in the Framingham Heart Study (16). This association was confirmed when replicating this SNP (rs10794108) in a cohort with comparable lung function. We have previously shown a significant relation between airway obstruction and airway wall thickening, both known features of COPD, in the NELSON cohort (4). The current finding that rs10794108 is associated with airway obstruction and with AWT supports our earlier finding.
The SNP rs734556 was also significantly associated with AWT, the risk allele $(\mathrm{G})$ associated with a lower SERPINE2 mRNA expression in lung tissue. This is of interest, because SERPINE2 was identified previously as a susceptibility gene for COPD and particularly emphysema $(3,17,18)$. SERPINE2 has been shown to inhibit extracellular matrix destruction (19). SNPs in this gene may influence alterations in repair of smoking-induced airway wall damage and our data suggest that this SNP may be involved in a common pathway of the origin of emphysema and AWT. However, we did not find a significant relationship between eQTL of SERPINE2 and lung function. One possible cause is the central endobronchial location instead of peripheral tissue obtained for the expression study. Central airway wall biopsies and no peripheral biopsies were taken in the GLUCOLD population in which everyone has COPD. SERPINE2 may be more important for peripheral airway obstruction and destruction as occurs in COPD that is accompanied by emphysema. Another cause may be that SERPINE2 is over shaded by the effects of other risk factors present in this population.

Another SNP showing a strong primary association with AWT was located in the

Table 6. Association of MAGI2 and NT5C3B Messenger RNA Expression Levels Assessed in Airway Wall Biopsies of Patients with Chronic Obstructive Pulmonary Disease $(n=79)$ with Lung Function and Bronchial Biopsy Inflammatory Markers

\begin{tabular}{|c|c|c|c|c|}
\hline & \multicolumn{2}{|c|}{ MAGI2 } & \multicolumn{2}{|c|}{ NT5C3B } \\
\hline & $t$ Value & $P$ Value & $t$ Value & $P$ Value \\
\hline $\begin{array}{l}\mathrm{FEV}_{1} \% \text { predicted (post-bronchodilator) } \\
\text { Neutrophils, } \mathrm{n} \\
\text { Macrophages, } \mathrm{n} \\
\text { Eosinophils, } \mathrm{n} \\
\text { Mast cells, } \mathrm{n} \\
\text { CD3 lymphocytes, } \mathrm{n} \\
\text { CD4 lymphocytes, } \mathrm{n} \\
\text { CD8 lymphocytes, } \mathrm{n} \\
\text { Intact epithelial cells, \% }\end{array}$ & $\begin{array}{r}0.80 \\
-1.31 \\
-2.62 \\
-0.36 \\
1.68 \\
-2.47 \\
-3.70 \\
-2.95 \\
-3.36\end{array}$ & $\begin{array}{l}4.24 \times 10^{-1} \\
1.95 \times 10^{-1} \\
1.08 \times 10^{-2} \\
7.20 \times 10^{-1} \\
9.71 \times 10^{-2} \\
1.57 \times 10^{-2} \\
4.08 \times 10^{-4} \\
4.22 \times 10^{-3} \\
1.24 \times 10^{-3}\end{array}$ & $\begin{array}{r}-2.19 \\
-0.31 \\
-1.48 \\
0.22 \\
-0.98 \\
0.44 \\
0.44 \\
-0.21 \\
-0.31\end{array}$ & $\begin{array}{l}3.17 \times 10^{-2} \\
7.55 \times 10^{-1} \\
1.44 \times 10^{-1} \\
8.26 \times 10^{-1} \\
3.31 \times 10^{-1} \\
6.59 \times 10^{-1} \\
6.61 \times 10^{-1} \\
8.31 \times 10^{-1} \\
7.61 \times 10^{-1}\end{array}$ \\
\hline
\end{tabular}

guanylate kinase $W W$ and PDZ domain containing 2 (MAGI2) gene, a large gene that encodes a scaffolding protein involved in the epithelial tight junction pathway (20). Cell membranes of epithelial cells join together forming a virtually impermeable barrier. Tight junctions are the most apically located of the intercellular junctions and play a critical role in epithelial barrier function (21). Therefore, variants in tight junction genes may affect this barrier function in the airways. Higher MAGI2 mRNA expression was also associated with less inflammatory cells in bronchial biopsies of patients with COPD. It could be speculated that the increased MAGI2 expression is a protective feedback function of the bronchial epithelial layer counteracting the weakened tight junctions by inhibiting local inflammation. Thereby it allows inhaled particles like cigarette smoke to penetrate less easily into the underlying tissue, causing inflammation and increased inflammation. This may subsequently lead to remodeling in the respiratory tract and thickening of the airways, particularly when this process takes place in the smaller airways, as present in COPD. Interestingly, SNPs in MAGI2 are also associated with inflammatory bowel disease supporting the hypothesis that diseases in which 
the integrity of the epithelium is affected share common underlying genetics $(22,23)$. It remains to be established in other cohorts with more severe emphysema whether MAGI2 also contributes to an increased peripheral AWT.

The SNP rs4796712 in the NT5C3B gene was second in rank of significance and encodes the enzyme cytosolic $5^{\prime}$ nucleotidase 3 . The functional studies showed that $N T 5 C 3 B$ is involved in airway wall thickening and thereby with airway obstruction. This is compatible with many studies showing that thicker airway walls are associated with worse airway obstruction (24-26).

The presence of rs4796712 had a significant effect on $N T 5 C 3 B$ lung tissue expression; the risk allele $(\mathrm{T})$ was associated with significantly higher $N T 5 C 3 B$ mRNA expression in lung tissue. Lower NT5C $3 B$ mRNA expression was associated with a worse obstruction in patients with COPD and the association of rs4796712 with AWT becomes stronger when more individuals with airway obstruction are included.

The risk allele in rs4796712 is associated with higher expression of NT5C3B in lung tissue. This seems to be in contradiction with the association of lower mRNA expression of NT5C $3 B$ with worse lung function $\left(3.17 \times 10^{-2}\right)$ in airway wall biopsies in GLUCOLD. However, these airway wall biopsies were performed in central airways. Airway obstruction is particularly important in the small airways, quite close to the location where we performed airway wall measurements. This may explain the discrepancy. For instance, some proteoglycans are differently present in small airways and large airways as we have previously shown for decorin in COPD (27).

NT5C $3 B$ encodes a $5^{\prime}$-nucleotidase, a member of the $5^{\prime}$-nucleotidase family of enzymes with different functions varying from a general role in maintaining balanced deoxyribonucleoside diphosphate and deoxyribonucleoside monophosphate pools to more tissue-specific functions, such as distribution of pyrimidine nucleotides during erythrocyte maturation and the formation of adenosine in different tissues (28). Adenosine has an important role in inflammation and tissue remodeling and promotes the formation or development of excess connective tissue in an injured organ thereby contributing to structural modifications of the architecture of different organs (29-31). In this way, increased levels of NT5C3B may contribute to airway wall thickening.
In summary, three significant loci on chromosomes 2q (rs734556 in SERPINE2) and 10q (rs10794108 and rs7078439, unknown function) were strongly associated with AWT in airways of $3.5-\mathrm{mm}$ internal diameter. Two nominally significant SNPs (rs10251504 in MAGI2 and rs4796712 in NT5C3B) showed effects with similar direction and were associated with AWT. eQTL were found in SERPINE2, a gene previously identified as a susceptibility gene for COPD, particularly emphysema; $N T 5 C 3 B$, a gene involved in maintaining nucleotides important for inflammation and tissue remodeling; and MAGI2, a gene involved in epithelial integrity and bronchial inflammation. Thus, our data support the notion that AWT is associated with genes involved in emphysema, bronchial inflammation, and tissue remodeling.

\section{Author disclosures are available with the text} of this article at www.atsjournals.org.

Acknowledgment: The authors thank all participants of the screening trials, and the research staff at Respiratory Health Network Tissue Bank of the Fonds de Recherche Québec-Santé for their valuable assistance in the lung expression quantitative trait loci study.

\section{References}

1. Nakano Y, Wong JC, de Jong PA, Buzatu L, Nagao T, Coxson HO, Elliott WM, Hogg JC, Paré PD. The prediction of small airway dimensions using computed tomography. Am J Respir Crit Care Med 2005;171: 142-146.

2. Patel BD, Coxson HO, Pillai SG, Agustí AG, Calverley PM, Donner CF, Make BJ, Müller NL, Rennard SI, Vestbo J, et al.; International COPD Genetics Network. Airway wall thickening and emphysema show independent familial aggregation in chronic obstructive pulmonary disease. Am J Respir Crit Care Med 2008;178:500-505.

3. Kim WJ, Hoffman E, Reilly J, Hersh C, Demeo D, Washko G, Silverman EK. Association of COPD candidate genes with computed tomography emphysema and airway phenotypes in severe COPD. Eur Respir J 2011;37:39-43.

4. Dijkstra AE, Postma DS, ten Hacken N, Vonk JM, Oudkerk M, van Ooijen PM, Zanen P, Mohamed Hoesein FA, van Ginneken B, Schmidt M, et al. Low-dose CT measurements of airway dimensions and emphysema associated with airflow limitation in heavy smokers: a cross sectional study. Respir Res 2013;14:11.

5. Washko GR, Dransfield MT, Estépar RS, Diaz A, Matsuoka S, Yamashiro T, Hatabu H, Silverman EK, Bailey WC, Reilly JJ. Airway wall attenuation: a biomarker of airway disease in subjects with COPD. J Appl Physiol (1985) 2009;107:185-191.

6. Mair G, Maclay J, Miller JJ, McAllister D, Connell M, Murchison JT, MacNee W. Airway dimensions in COPD: relationships with clinical variables. Respir Med 2010;104:1683-1690.

7. Grydeland TB, Dirksen A, Coxson HO, Pillai SG, Sharma S, Eide GE, Gulsvik A, Bakke PS. Quantitative computed tomography: emphysema and airway wall thickness by sex, age and smoking. Eur Respir J 2009;34:858-865.
8. van Klaveren RJ, Oudkerk M, Prokop M, Scholten ET, Nackaerts K Vernhout $R$, van lersel CA, van den Bergh KA, van 't Westeinde $S$, van $\operatorname{der}$ Aalst $\mathrm{C}$, et al. Management of lung nodules detected by volume CT scanning. N Engl J Med 2009;361:2221-2229.

9. Becker N, Motsch E, Gross ML, Eigentopf A, Heussel CP, Dienemann H, Schnabel PA, Pilz L, Eichinger M, Optazaite DE, et al. Randomized study on early detection of lung cancer with MSCT in Germany: study design and results of the first screening round. $J$ Cancer Res Clin Oncol 2012;138:1475-1486.

10. Quanjer PH, Tammeling GJ, Cotes JE, Pedersen OF, Peslin R, Yernault JC. Lung volumes and forced ventilatory flows. Report Working Party Standardization of Lung Function Tests, European Community for Steel and Coal. Official Statement of the European Respiratory Society. Eur Respir J Suppl 1993;16:5-40.

11. Gietema HA, Schilham AM, van Ginneken B, van Klaveren RJ, Lammers JW, Prokop M. Monitoring of smoking-induced emphysema with CT in a lung cancer screening setting: detection of real increase in extent of emphysema. Radiology 2007;244:890-897.

12. Hao K, Bossé Y, Nickle DC, Paré PD, Postma DS, Laviolette M, Sandford A, Hackett TL, Daley D, Hogg JC, et al. Lung eQTLs to help reveal the molecular underpinnings of asthma. PLoS Genet 2012;8: e1003029.

13. Lapperre TS, Snoeck-Stroband JB, Gosman MM, Jansen DF, van Schadewijk A, Thiadens HA, Vonk JM, Boezen HM, Ten Hacken NH, Sont JK, et al.; Groningen Leiden Universities Corticosteroids in Obstructive Lung Disease Study Group. Effect of fluticasone with and without salmeterol on pulmonary outcomes in chronic obstructive pulmonary disease: a randomized trial. Ann Intern Med 2009;151:517-527.

14. van den Berge M, Steiling K, Timens W, Hiemstra PS, Sterk PJ, Heijink $\mathrm{IH}$, Liu G, Alekseyev YO, Lenburg ME, Spira A, et al. Airway gene 
expression in COPD is dynamic with inhaled corticosteroid treatment and reflects biological pathways associated with disease activity. Thorax 2014;69:14-23.

15. Purcell S, Neale B, Todd-Brown K, Thomas L, Ferreira MA, Bender D, Maller J, Sklar P, de Bakker PI, Daly MJ, et al. PLINK: a tool set for whole-genome association and population-based linkage analyses. Am J Hum Genet 2007;81:559-575.

16. Wilk JB, Chen TH, Gottlieb DJ, Walter RE, Nagle MW, Brandler BJ, Myers RH, Borecki IB, Silverman EK, Weiss ST, et al. A genome-wide association study of pulmonary function measures in the Framingham Heart Study. PLoS Genet 2009;5:e1000429.

17. DeMeo D, Mariani T, Lange C, Lake S, Litonjua A, Celedón J, Reilly J, Chapman HA, Sparrow D, Spira A, et al. The SERPINE2 gene is associated with chronic obstructive pulmonary disease. Proc Am Thorac Soc 2006;3:502.

18. Kukkonen MK, Tiili E, Hamalainen S, Vehmas T, Oksa $P$, Piirila $P$ Hirvonen A. SERPINE2 haplotype as a risk factor for panlobular type of emphysema. BMC Med Genet 2011;12:157.

19. Bergman BL, Scott RW, Bajpai A, Watts S, Baker JB. Inhibition of tumor-cell-mediated extracellular matrix destruction by a fibroblast proteinase inhibitor, protease nexin I. Proc Natl Acad Sci USA 1986; 83:996-1000.

20. Wu X, Hepner K, Castelino-Prabhu S, Do D, Kaye MB, Yuan XJ, Wood J, Ross C, Sawyers CL, Whang YE. Evidence for regulation of the PTEN tumor suppressor by a membrane-localized multi-PDZ domain containing scaffold protein MAGI-2. Proc Natl Acad Sci USA 2000; 97:4233-4238.

21. Hogg JC, Timens W. The pathology of chronic obstructive pulmonary disease. Annu Rev Pathol 2009;4:435-459.

22. Wapenaar MC, Monsuur AJ, van Bodegraven AA, Weersma RK, Bevova MR, Linskens RK, Howdle P, Holmes G, Mulder CJ, Dijkstra $\mathrm{G}$, et al. Associations with tight junction genes PARD3 and MAGI2 in Dutch patients point to a common barrier defect for coeliac disease and ulcerative colitis. Gut 2008;57:463-467.
23. McGovern DP, Taylor KD, Landers C, Derkowski C, Dutridge D, Dubinsky M, Ippoliti A, Vasiliauskas E, Mei L, Mengesha E, et al. MAGI2 genetic variation and inflammatory bowel disease. Inflamm Bowel Dis 2009;15:75-83.

24. Kim WJ, Silverman EK, Hoffman E, Criner GJ, Mosenifar Z, Sciurba FC, Make BJ, Carey V, Estépar RS, Diaz A, et al.; NETT Research Group. CT metrics of airway disease and emphysema in severe COPD. Chest 2009;136:396-404.

25. Nakano Y, Muro S, Sakai H, Hirai T, Chin K, Tsukino M, Nishimura K, Itoh $\mathrm{H}$, Paré PD, Hogg JC, et al. Computed tomographic measurements of airway dimensions and emphysema in smokers. Correlation with lung function. Am J Respir Crit Care Med 2000;162: 1102-1108.

26. Hasegawa M, Nasuhara $Y$, Onodera $Y$, Makita $H$, Nagai $K$, Fuke $S$, Ito $\mathrm{Y}$, Betsuyaku T, Nishimura M. Airflow limitation and airway dimensions in chronic obstructive pulmonary disease. Am J Respir Crit Care Med 2006;173:1309-1315.

27. Brandsma CA, Timens W, Jonker MR, Rutgers B, Noordhoek JA, Postma DS. Differential effects of fluticasone on extracellular matrix production by airway and parenchymal fibroblasts in severe COPD. Am J Physiol Lung Cell Mol Physiol 2013;305: L582-L589.

28. Hunsucker SA, Mitchell BS, Spychala J. The 5'-nucleotidases as regulators of nucleotide and drug metabolism. Pharmacol Ther 2005; 107:1-30.

29. Mohsenin A, Blackburn MR. Adenosine signaling in asthma and chronic obstructive pulmonary disease. Curr Opin Pulm Med 2006; 12:54-59.

30. Caruso M, Alamo A, Crisafulli E, Raciti C, Fisichella A, Polosa R Adenosine signaling pathways as potential therapeutic targets in respiratory disease. Expert Opin Ther Targets 2013;17:761-772.

31. Della Latta V, Cabiati M, Rocchiccioli S, Del Ry S, Morales MA. The role of the adenosinergic system in lung fibrosis. Pharmacol Res 2013;76: 182-189. 